Oikos 000: 001-007, 2010

doi: 10.1111/j.1600-0706.2010.18983.x

(C) 2010 The Authors. Oikos (C) Nordic Society Oikos

Subject Editor: Stan Boutin. Accepted 5 October 2010

\title{
Delayed density-dependent onset of spring reproduction in a fluctuating population of field voles
}

\author{
Torbjørn Ergon, Rolf Ergon, Mike Begon, Sandra Telfer and Xavier Lambin \\ T. Ergon, Program for integrative biology, Dept of Biology, Univ. of Oslo, PO Box 1066 Blindern, NO-0316 Oslo, Norway. - R. Ergon, \\ Telemark Univ. College, PO Box 203, NO-3931 Porsgrunn, Norway. - M. Begon, School of Biological Sciences, The Univ. of Liverpool, \\ Liverpool, L69 7ZB, UK. - S. Telfer and X. Lambin (x.lambin@abdn.ac.uk), School of Biological Sciences, Univ. of Aberdeen, Zoology \\ Building, Tillydrone Avenue, aberdeen, AB24 2TZ, UK.
}

\begin{abstract}
Delayed density-dependent demographic processes are thought to be the basis for multi-annual cyclic fluctuations in small rodent populations, but evidence for delayed density dependence of a particular demographic trait is rare. Here, using capture-recapture data from 22 sites collected over nine years, we demonstrate a strong effect of population density with a one-year lag on the timing of the onset of spring reproduction in a cyclically fluctuating population of field voles Microtus agrestis in northern England. The mean date for the onset of spring reproduction was delayed by about 24 days for every additional 100 voles ha $^{-1}$ in the previous spring. This delayed density dependence is sufficient to generate the type of cyclic population dynamics described in the study system.
\end{abstract}

It is now generally accepted that population regulation can only be due to mechanistic links between present and/or past population densities and per capita population growth (Murdoch 1994, Turchin 1995). Nevertheless, such density dependence may not be easy to detect. First, population growth may be held back most of the time by density independent processes so that populations only occasionally reach densities where density dependent factors are strong enough to be detected (Turchin 1995). Second, density dependent mechanisms may act with a time-delay and may thus be less obvious (Murdoch 1994, Berryman 2002b, Turchin 2003).

The long term dynamics of a population can be viewed as a stochastic process affected by direct and delayed density dependence together with density independent environmental effects (Royama 1992, Stenseth 1999). When delayed density dependent negative feedback is sufficiently strong and with a long enough time-lag, the population dynamics may in certain circumstances be inherently cyclic (Berryman 2002b, Turchin 2003). Indeed, most evidence of delayed density dependence comes from studies of cyclic populations of vertebrates and insects (Berryman 2002a). Further, it has been argued that delayed density dependence in cyclic populations is generally caused by trophic interactions rather than intrinsic mechanisms in the population (Berryman 2002a, Turchin 2003).

Different ecological processes are expected to affect different demographic traits, and these effects may be season and age specific. Thus, the demographic syndrome observed in a fluctuating population is more informative with respect to the underlying ecological process than changes in population size (Oli and Dobson 2001, Dobson and Oli 2001, CluttonBrock and Coulson 2002, Benton et al. 2006). Indeed, widely different ecological processes may result in identical or similar density dependent structure and emerging dynamics at the population level (McCauley and Murdoch 1987, Lambin et al. 2002).

Several analyses of small rodent time-series of spring- and autumn abundance data have concluded that delayed density dependence acting on the populations from autumn to spring is an indispensable feature of the population cycles in the studied systems (Stenseth 1999, Stenseth et al. 2003, Bierman et al. 2006, Saitoh et al. 2006). In northern latitude areas where reproduction often starts long before snowmelt, spring abundance data are often obtained after the onset of the reproductive season. Thus, apparent delayed density dependence during the winter season may reflect effects on either winter survival and/or reproduction in the spring.

In this study, by contrast, we focus explicitly on the timing of reproductive commencement after the winter. Although this is a demographic trait that shows particularly large variation amongst overwintering cohorts in cyclic populations (Krebs and Myers 1974, Ergon et al. 2009), and in which delayed density dependence is sufficient to generate multi-annual population cycles in small rodents (Smith et al. 2006), the empirical density dependent structure of the variation in this trait has not previously been well described. Here we use capture-mark-recapture data from cyclic populations of field voles Microtus agrestis in Kielder Forest, northern England. We estimated the date that $50 \%$ of females had given birth for their first time during spring, and partitioned 
the variation in onset of spring reproduction into density dependent and density independent components as well as measurement error. We can thus evaluate the importance of delayed density dependence of this demographic component for generating multi-annual population fluctuations. Although we do not directly address the specific mechanisms behind the variation in onset of spring reproduction, we discuss the potential relevance of various hypothesized mechanisms in the study system.

\section{Methods}

\section{Study system and data}

Kielder Forest is a large spruce plantation $\left(>600 \mathrm{~km}^{2}\right)$ on the border between England and Scotland. Field voles Microtus agrestis, by far the most numerous small rodents in the area, are confined to distinct grass covered clear-cuts enclosed by dense tree stands that are uninhabitable for voles because they lack ground vegetation. Field voles are microtine rodents (Subfamily Arvicolinae) relying primarily on grasses as forage. Female field voles in the spring may give birth repeatedly at about 20 days interval under good conditions (Ergon et al. 2001b), and offspring born in spring may conceive their first litter immediately after weaning (at 2-3 weeks of age). Survival rates are generally low and very few individuals live as long as a year in the field (Graham and Lambin 2002). Field vole sub-populations in Kielder forest fluctuate somewhat asynchronously but nevertheless with a characteristic period of 3-5 years (Lambin et al. 2000, Bierman et al. 2006), making the area particularly well suited for replicated studies on the direct and delayed density-dependence of demographic traits. Studies of wintering voles and the onset of spring reproduction are also made easy by the absence of permanent snow cover during winter (detailed description of the study system in (Lambin et al. 2000, Graham and Lambin 2002). Green vegetation in winter is dominated by the semi perennial grass Descampsia caespitosa and by Juncus effusus.

We made use of capture-recapture data of field voles collected over a period of nine years (1996 to 2004) from 22 different forest clear-cuts (sites) in Kielder Forest. The data from each site covered one to six years, giving 47 datasets defined by a unique site and year. Each dataset consisted of individual capture records taken from one to six primary trapping sessions (separated by two to four weeks) that took place before the capture of the first juveniles in the spring. These data were used to estimate the population-level time of onset of spring reproduction. For estimation of population density and population growth rate, we used, in addition, data from September and October. All but six of the datasets originated from monitoring of 0.3 ha trapping grids. The sampling protocol is described in Lambin et al. (2000) and Graham and Lambin (2002). The remaining datasets resulted from monitoring of 1.0-1.2 ha trapping grids (methods in Ergon et al. 2001a).

\section{Estimation of density and population growth}

Most datasets included data from five secondary trapping sessions within each primary session (two to three days of trapping), and abundance estimates were obtained from closed capture-recapture models in program Capture (Rexstad and Burnham 1991). We used a model accounting for temporal variation and individual heterogeneity in capture probability: the $\mathrm{M}^{\text {th }}$ model of Chao et al. (1992). Abundance estimates from one site in the years 2000 and 2003 (site F) and five sites in 2004 (sites F, J, T, U and V) were obtained from robust design models in program Mark (White and Burnham 1999) because these data had been collected with fewer secondary trapping sessions. We here used a model accounting for variation in capture probability depending on time of day (morning/evening) and functional group of the individuals (sex and juvenile/adult). The abundance estimates were converted to density estimates by dividing the estimates by the area covered by the trapping grids including a five $\mathrm{m}$ boundary strip outside of the outermost traps.

As a measure of spring density, we used average density estimates for the months of March and April. For summer densities we used May-June averages, and for autumn densities September-October. Averaging over two consecutive months was done to reduce the variation in the dates (days of the year) for which density estimates were obtained as well as sampling variation in the density estimates (standard deviation of the averaged dates was 10 days for spring, 12 days for summer and 7 days for autumn). We then calculated population growth rates from one season to the next as $\ln \left(\hat{\mathrm{N}}_{2} / \hat{\mathrm{N}}_{1}\right) / \Delta \mathrm{t}$, where $\hat{\mathrm{N}}_{2}$ and $\hat{\mathrm{N}}_{1}$ are the averaged density estimates for the two seasons, and where $\Delta t$ is the time between the two averaged dates. We only use population growth rate in a correlation analysis in this paper, but we acknowledge at the outset that our seasonal population growth rates inevitably combine the effects of different processes that may be offset in time. For example, 'population growth' from spring to summer is a variable combination of late winter decline that may sometimes extend into March-April or beyond, and an early-summer increase reflecting the recruitment of the first cohorts of juveniles born in spring. This, though, is true of all such growth rates analyzed in the literature.

\section{Estimates of onset of spring reproduction}

As a site-level measure of onset of spring reproduction, we used the estimated date when $50 \%$ of the females known to be alive at the site had given birth and were lactating for the first time in the spring. We estimated this with a logistic regression of proportions of postpartum females on sampling date (methods in Ergon et al. 2001a). Because of the large number of datasets (47) with few trapping occasions per data set (one to six) a model with different slopes would not be supported by the data, hence we used a model with a common slope for all datasets. Confidence intervals around the coefficients of correlation between mean parturition date and estimates of population density and growth rate were obtained by standard non-parametric bootstrapping with 10000 re-samples.

Proportions of animals known to be alive that are postpartum are affected by differences in both capture probability and survival of animals in the two reproductive states. Estimates of capture probability were generally above $80 \%$ (Graham and Lambin 2002, Ergon 2007, Ergon et al. 2009). Although reproducing animals are somewhat more trappable 
than non-reproducing animals, there is no evidence this difference varies between site and years. Survival differences between pre- and postpartum animals could potentially depend on environmental conditions that vary between sites and years. However, we expect this to have a relatively weak influence on the proportions of postpartum females in the population compared to the extensive variation in this measurement. More sophisticated methods to estimate the latent distribution of individual maturation times from longitudinal capture-recapture data (Ergon et al. 2009) were not used because we lacked repeated data on individuals for many of the data sets. For the current analysis, we found it more important to include data from many sites and years.

\section{Estimation of density dependence of mean parturition date}

We sought to estimate the linear effect of present and previous population densities on onset of spring reproduction. Total least squares (TLS) (Van Huffel et al. 2007) is an estimation method well suited for cases with measurement errors in both the predictor (here density) and response variables (here date when $50 \%$ of the females known to be alive at the site had given birth for the first time), particularly as we are interested in the parameters of the model only, not in prediction. In the present case, where the measurement errors differed between data points, we applied the recently developed method 'elementwise weighted total least squares' (EW-TLS) (Markovsky et al. 2006). This method does not, however, allow for unexplained process variation (i.e. random variation in the expectations between sites and years). We therefore included the EW-TLS fit in a normal likelihood function, with the random process variance being modeled as an exponential of a linear model. The process variance, together with the estimated error variances of the y-values (taken as given), made up the weights used to obtain the EW-TLS fit. This likelihood function was maximized with a simplex method (function 'fminsearch') in the Optimization toolbox of Matlab (ver. 7.8.0) (<www.mathworks.com/>); see Supplementary material Appendix 1 for the Matlab code. Confidence intervals of all parameters were estimated by ordinary non-parametric bootstrapping.

It is difficult to implement a model with separate variance components for years and sites in the approach outlined above. To tease these two sources of variation apart, we therefore instead examined the variance components of residuals of the model. Variance components were estimated by the 'Imer' function in the 'Ime4' package (ver. 0.9) of R $(<\mathrm{http} / / /$ cran.ii.uib.no/ $>$ ), and HPD confidence intervals were obtained by MCMC-simulations (function 'mcmcsamp' in 'Ime4'). Finally, we included the fixed additive effects of year and site in the model to assess potential confounding between these effects and density dependence.

\section{Results}

Over the nine years covered by the data (Fig. 1), spring densities at the 22 different sampling sites varied between 27 and 278 voles ha ${ }^{-1}$ and autumn densities ranged from 20 to 765 voles ha $^{1}$ (standard error of the density estimates ranged
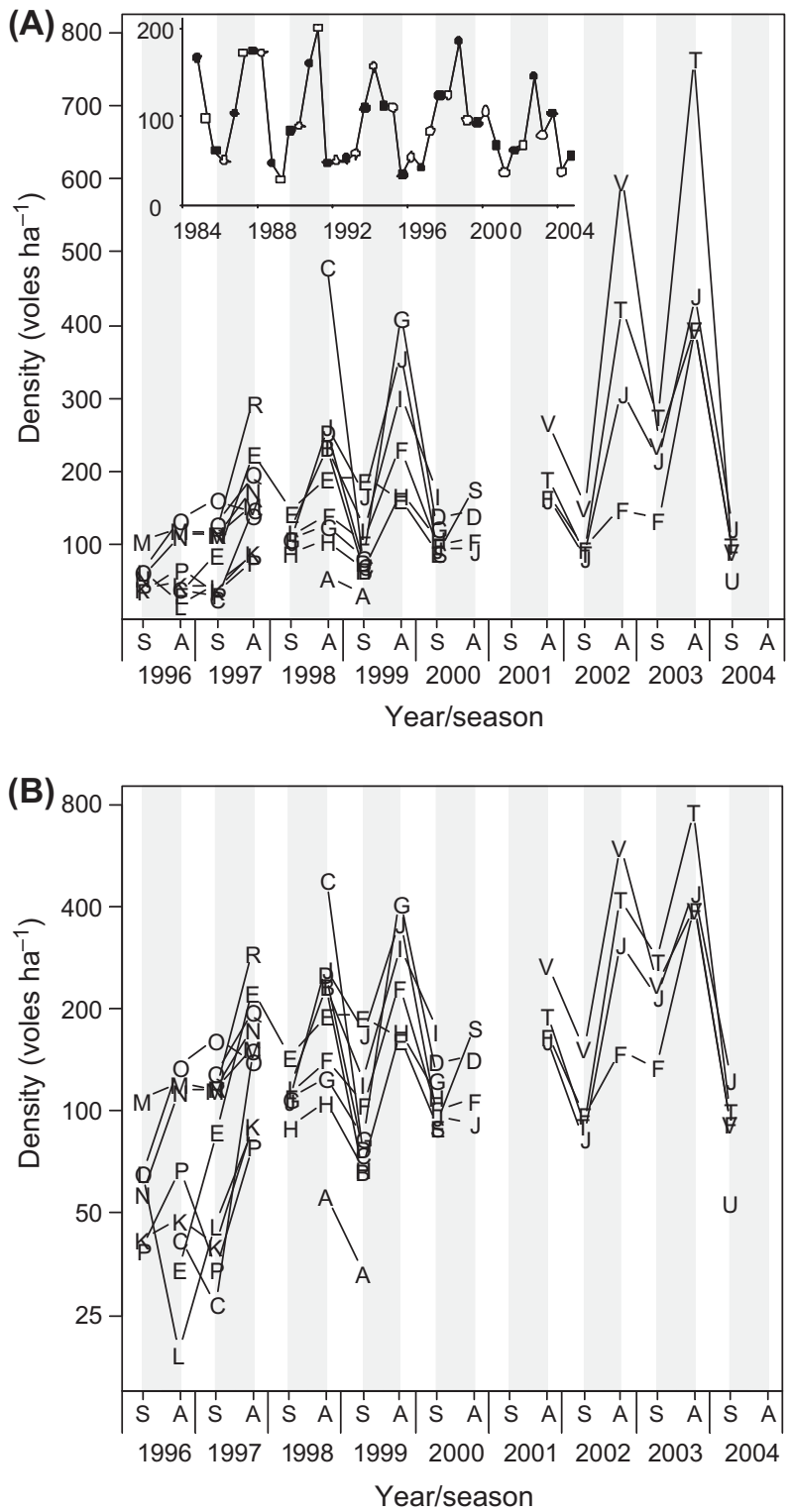

Figure 1. Population density estimates at the 22 sampling sites (labels A to V) during spring (S) and autumn (A) plotted on a linear scale (panel A) and on a log-scale (panel B). Top left inset shows estimates of spring (open symbols) and autumn (filled symbols) densities averaged over minimum 18 sites in the Kielder forest region per year (methods in Lambin et al 2000).

from $2 \%$ to $22 \%$ of the point estimates). Estimates of the date when $50 \%$ of the females known to be alive in a site had given birth for the first time after the winter ranged from March 17 to June 6 ( 81 days between the extremes). About $15 \%$ of the variance among these estimates was due to measurement error. Within sites in a given year, the estimated time from the date when $5 \%$ of the females were postpartum to the date when $95 \%$ were postpartum spanned 50 days (95\% CI: 46 to 55 days).

In Fig. 2, the estimates of mean parturition date are plotted against estimates of past and present population densities, as well as estimates of season specific population growth. Mean parturition date is most strongly correlated with population density in the previous spring (panel A) 


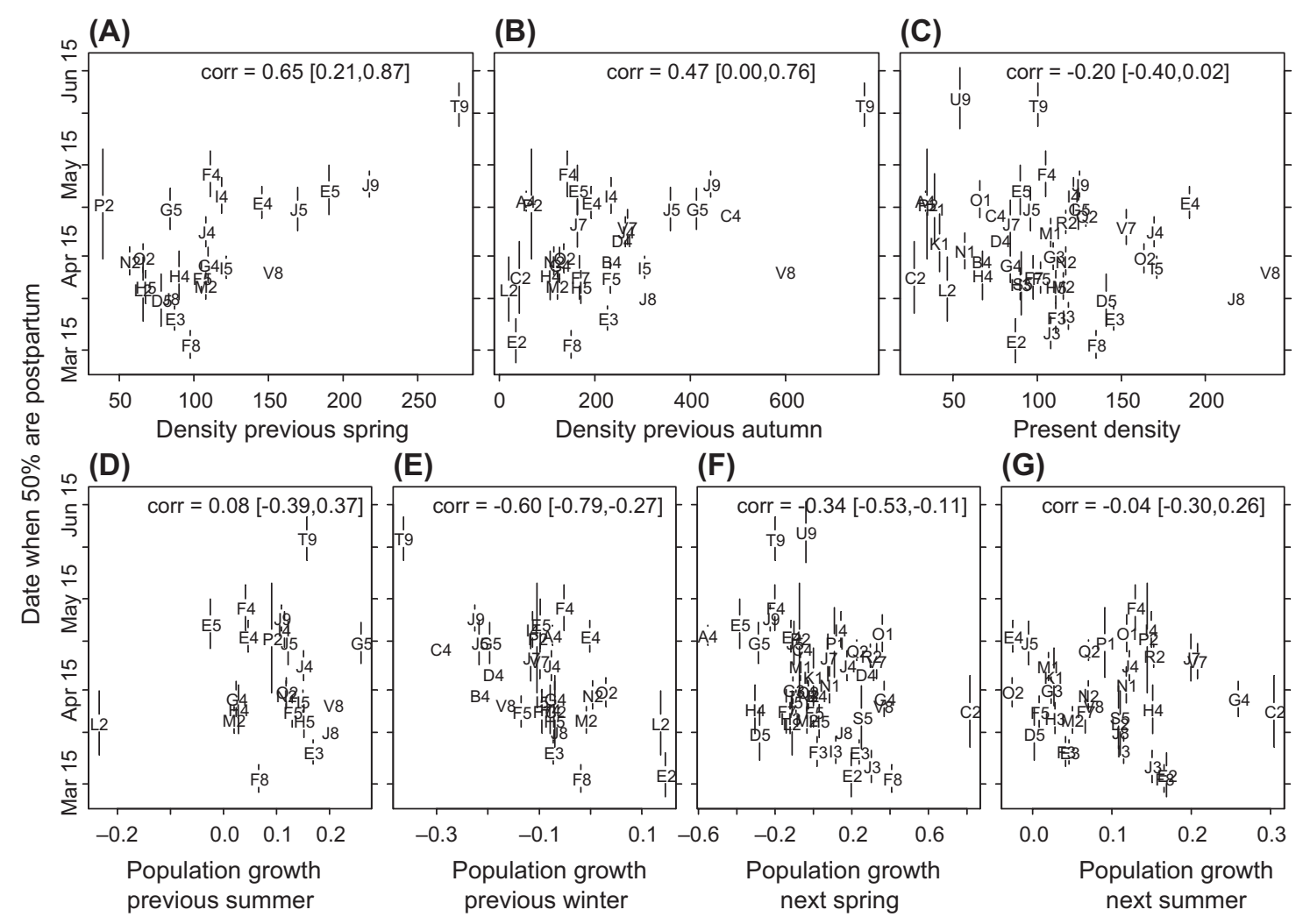

Figure 2. Estimated dates when $50 \%$ of the females in a site were post-partum in year t plotted against estimates of (A) density in the previous spring (March/April of year t-1), (B) density in the previous autumn (September/October of year t-1), (C) density in the present spring (March/April of year t), (D) population growth from May/June to September/October in year t-1, (E) population growth from September/ October in year $t-1$ to March/April in year $t,(F)$ population growth from March/April to May/June in year $t$, and $(G)$ population growth from May/June to September/October in year t. Population growth rates are on a monthly time-scale. Error bars show \pm SE (when missing, $\mathrm{SE}$ is smaller than the symbol). Plotted labels represent site (letters corresponding to the labels in Fig. 1) and year (numbers; $1=1996, \ldots$, $9=2004$ ). $95 \%$ bootstrap CI of correlation coefficients are given at the top of each panel.

and population decline during the previous winter season (panel E). Spring reproduction is delayed after high population densities in the previous year and after steep population declines over the previous winter.

There is indeed a much larger variation in the population growth rate during the spring than during any other season (note different $\mathrm{x}$-axes in Fig. 2): the standard deviation of population growth rate per time in the spring is 2.8 times higher than in the summer (95\% bootstrap CI: 1.8 to 4.2) and 2.9 times higher than in the winter $(95 \%$ bootstrap CI: 1.8 to 4.4), meaning that relative change in population size over the two spring months varies about as much as the relative change over the four summer months and the six winter months. Furthermore there is a negative correlation between onset of reproduction and population growth during the same spring (March/April to May/June; panel F). There is however no significant correlation between onset of reproduction and population growth during the following summer season (May/June to September/October; panel G).

On average, spring reproduction is delayed by 24 days (95\% CI: 13 to 31 days) for every additional 100 voles ha ${ }^{-1}$ in the previous spring (Table 1). About $58 \%$ of the variation in mean parturition date (measurement error variance excluded) can be explained by a linear model including past spring densities alone, and the additional effects of past autumn densities and present spring densities do not significantly improve the fit of the regression model (Table 1 ). There is no evidence of delayed reproduction when current spring densities are high. On the contrary, low densities tend to be associated with late reproduction (Table 1) in that steep winter declines (and hence low spring densities) tend to be followed by late onset of reproduction (Fig. 2 panel E).

The standard deviation of the unexplained variation among sites and years (measurement error variance excluded) was 11.2 days ( $95 \%$ CI: 6.8 to 14.3 ). Variance component analysis of the residuals of model 1 (Table 1 ) showed that up to $54 \%$ (point estimate: $25.2 \%$; $95 \%$ CI: $0.0 \%$ to $53.3 \%$ ) of this residual process variance was attributed to betweenyear variation (e.g. caused by climate effects), whereas less than $10 \%$ of the residual process variance (point estimate: $0.0 \%$; $95 \%$ CI: $0.0 \%$ to $9.8 \%$ ) was attributed to betweensite variation, possibly reflecting the similar vegetation in each site.

Inspection of Fig. 2 shows that a potential confounding between site-differences and delayed density dependent effects is not a concern (note the site labels). On the other hand, year-differences could potentially bias the estimates of density dependence since the populations at the different sites do not fluctuate completely independently (Fig. 1). However, when 'year' was included in the model as a fixed effect, the effect of past spring densities within years (parallel slopes model) was still significant and comparable to the 
Table 1. Parameter estimates $(95 \% \mathrm{Cl})$ for different models of mean parturition date. Confidence intervals that do not include zero are in bold.

\begin{tabular}{|c|c|c|c|c|c|c|}
\hline Model & $\begin{array}{l}\text { Intercept } \\
\text { (SE in days) }\end{array}$ & $\begin{array}{c}\text { Past spring } \\
\text { density (days per } \\
100 \text { voles ha-1) }\end{array}$ & $\begin{array}{l}\text { Past autumn } \\
\text { density (days per } \\
100 \text { voles ha }{ }^{-1} \text { ) }\end{array}$ & $\begin{array}{c}\text { Present } \\
\text { density (days per } \\
100 \text { voles ha-1) }\end{array}$ & $\begin{array}{c}\text { Random } \\
\text { variation* } \\
\text { (SD in days) }\end{array}$ & $\begin{array}{l}\text { Proportion of } \\
\text { variance } \\
\text { explained }\end{array}$ \\
\hline 1. Past spring density (PSD) & $20 \operatorname{Mar}(6.4)$ & $23.9[12.7,30.7]$ & & & $11.2[6.8,14.3]$ & 0.58 \\
\hline 2. Past autumn density (PAD) & 06 Apr (5.5) & & $4.8[0.0,8.2]$ & & $13.6[9.1,16.2]$ & 0.25 \\
\hline 3. Present density $(\operatorname{PrD})$ & 26 Apr (5.7) & & & $-7.8[-17.4,0.9]$ & $15.5[11.5,18.9]$ & 0.07 \\
\hline 4. PSD + PAD & $21 \operatorname{Mar}(7.0)$ & $25.6[9.2,42.2]$ & $-0.9[-6.6,4.9]$ & & $11.3[5.9,14.2]$ & 0.57 \\
\hline 5. $\mathrm{PSD}+\operatorname{PrD}$ & 01 Apr (9.0) & $24.1[16.0,31.1]$ & & $-8.8[-17.0,2.0]$ & $10.6[5.9,13.5]$ & 0.63 \\
\hline 6. $\mathrm{PAD}+\operatorname{PrD}$ & 18 Apr (6.8) & & $6.4[2.2,9.5]$ & $-13.5[-24.7,0.2]$ & $12.1[7.9,14.3]$ & 0.42 \\
\hline 7. $P S D+P A D+\operatorname{PrD}$ & 04 Apr (13.1) & $20.3[1.1,41.1]$ & $1.5[-6.8,8.9]$ & $-10.1[-26.9,5.4]$ & $10.7[5.2,13.2]$ & 0.65 \\
\hline
\end{tabular}

*estimated unexplained random variation (measurement error excluded) among site $\times$ years expressed as standard deviation (unit of days). tproportion of total process variance (estimated measurement error variance subtracted) explained by the model. Values are not directly comparable across models because slightly different subset of the data are used due to missing values in the predictor variables.

overall effect: spring reproduction delayed by 21.5 days (95\% CI: 2.8 to 36.7 days) for every additional 100 voles $\mathrm{ha}^{-1}$ in the previous spring.

\section{Discussion}

Using detailed capture-recapture data collected over nine years in cyclic field vole populations from 22 semi-isolated grassland sites experiencing semi-synchronous dynamics, we detected a very strong effect of previous spring densities (one year lag) on the onset of spring reproduction: the date when $50 \%$ of the females had given birth to their first litter of the year varied by more than two months. On average, spring reproduction was delayed by 24 days for every additional 100 voles $\mathrm{ha}^{-1}$ in the previous spring, where spring densities typically range from about 20 to 300 voles ha- ${ }^{-1}$. Considering that female field voles in the spring may give birth repeatedly at about 20 days interval under good conditions (Ergon et al. 2001b), and that offspring born in spring may conceive their first litter immediately after weaning (at 2-3 weeks of age), the potential significance of this variation on population dynamics is substantial.

Our analysis also shows that population growth rate is more variable in the spring than in any other season, and that late onset of reproduction is associated with spring declines in population density. This suggests that variation in onset of spring reproduction may contribute significantly to the multi-annual density fluctuations in these populations. Although we have not attempted to compare the contributions of the various season-specific demographic processes in this study, we note that other studies in this study system have demonstrated that survival rates vary more between seasons than between years, with lower survival rates in the spring than in other seasons (Graham and Lambin 2002, Burthe et al. 2008).

\section{Implications for population dynamics}

Whereas cyclic phase-specific changes in reproductive traits have long been recognized in cyclic vole populations (Krebs and Myers 1974) as well as in populations of mice with erratic outbreaks (Singelton et al. 2001), the delayed density dependent pattern in the commencement of the breeding season has not previously been quantified. Still, changes in the length and intensity of the summer breeding season have been claimed to be an epiphenomenon of rodent cycles, with little demographic importance (Norrdahl and Korpimäki 2002). In stark contrast, using the same magnitude of delayed density dependence in variation in spring maturation as presented in this paper, Smith et al. (2006) formulated analytical models to explore the dynamical implications of delayed density dependent breeding season length and found that these models readily yield 3-4 year cycles similar to those seen in Kielder Forest in terms of periodicity, amplitude and density during the low phase. These models simply assumed that exponential growth takes place over a breeding season of varying length and that populations decay exponentially when no reproduction takes place. The models do not invoke any changes in birth rates or survival. Thus, the combination of empirical and modeling evidence establishes that density-dependent feedback acting from spring to spring on a single demographic trait, the relative length of the breeding and non-breeding seasons, may account for the delayed feedback on population growth from one year to the next in multi-annual cycles such as those observed in Kielder Forest (Bierman et al. 2006).

\section{Potential mechanisms for effects of past densities on onset of spring reproduction}

Arvicoline rodents have notoriously flexible life histories, with plastic maturation strategies similar to facultative diapause: individuals may either mature rapidly at a young age (the typical strategy in the spring) or delay maturation for many months until the next breeding season (the typical strategy from mid-summer onward) (Innes and Millar 1995, Ergon et al. 2001b). Individuals that delay maturation suspend growth at a sub-adult stage and have a much higher probability of surviving the winter than large voles that have already matured (Hansson 1992, Aars and Ims 2002). At the onset of reproduction in the spring, sub-adult voles resume growth and mature rapidly (Ergon et al. 2001a). In this paper, we have demonstrated a very substantial variation in the time that this onset of spring reproduction takes place. However, we know little about the ecological and physiological mechanisms for this variation, and we only have general ideas about the potential ecological processes that may lead to the delayed density-dependent patterns. 
Mechanisms for delayed density-dependence are often separated into intrinsic processes within the population (prolonged changes in the state of the individuals or structure of the population), and extrinsic processes, usually involving trophic interactions. A large scale reciprocal transplant experiment performed in early winter in our study system (Ergon et al. 2001a) showed that onset of spring reproduction is a function of the immediate environment and not the source population of the individuals. We have thus reasons to believe that intrinsic processes (Chitty 1967) are not important causes of delayed density-dependent variation in spring reproduction in our study system. Instead, the memory of past conditions, leading to delayed density-dependence in onset of spring reproduction, must reside in the environment experienced by the voles when they initiate reproduction in the spring.

It has been suggested that predation may have non-lethal impacts on prey through reduced prey foraging activity when the risk of predation is high, leading to delayed reproduction (Ylönen 1994, Lima 1998). Reduced activity entails lower energy expenditure relative to body mass. However, we have observed the opposite pattern in our study system: in sites where voles commenced spring reproduction late, the voles had substantially elevated field energy expenditure (Ergon et al. 2004), despite a smaller body size than in sites where reproduction commenced early. Furthermore, there is no evidence of any time lag between field vole and common weasel dynamics in Kielder Forest (Graham and Lambin 2002). Hence, predation by this specialist vole predator can be dismissed as explanation for the pattern of variation in reproduction reported here.

Voles maintain a low body mass through the winter probably due to low energy availability during this time of the year (Hansson 1990, Ergon et al. 2004), and early reproduction is likely to be constrained by limited energy intake during winter/early spring (Bronson and Heideman 1994). Indeed, several food supplement field experiments have succeeded in advancing the onset of the breeding season (reviewed by Boutin 1990), and late onset of reproduction in Kielder field voles appears to be associated with both lower over-winter body mass and slower body growth in the spring (Ergon et al. 2001a). Variation in food energy availability during early spring and hence in onset of spring reproduction in voles can be due to variation in the nutritional quality of the early emerging grasses, or it can be due to variation in the phenology of the food plants (i.e. the timing of the emergence of new shoots in the spring). It is well established that reproduction in many species of Microtus voles can be triggered by small amounts of the phenolic compound 6-MBOA in their food plants (Berger et al. 1981, Sanders et al. 1981). This compound, which has no nutritional value, is associated with the growth of grasses and thus serves as a cue that enables the voles to initiate reproduction at an early phenological stage of their food plants. Experimental provisioning of 6-MBOA to Microtus townsendii populations advanced reproduction by four weeks compared to control (Korn and Taitt 1987). Thus, it is not implausible that some of the substantial between-year variation in onset of spring reproduction that we have documented in our study may have been caused by variation in the phenology of the food plants. However, we are not aware of any studies that document any delayed effect of vole grazing on the spring phenology of the food plants, which could potentially cause the delayed density dependence in onset of spring reproduction in the voles. Alternatively, delayed or prolonged reductions in the nutritional quality of the food plants resulting from heavy grazing (Karban and Baldwin 1997), and possibly mediated by induction of silica uptake by grasses may delay the time when voles are able to commence reproduction in early spring (Massey et al. 2008).

Finally, pathogens such as cowpox and vole tuberculosis are highly prevalent in our study populations (Telfer et al. 2007, Burthe et al. 2008). Infections by such pathogens are known to delay maturation (Telfer et al. 2005) and might thus contribute to variation in the onset of spring reproduction. Since infection state varies among individuals within sites, it is plausible that some of the large variation in onset or reproduction within sites (about 50 days between the 5\% and the $95 \%$ quantiles of the distribution) could be related to pathogenic effects. However, since variation in the mean date for the onset of spring reproduction among sites and years is substantially larger this, pathogens cannot plausibly be responsible alone for the variations at the population level.

Hence, while we have identified substantial delayed density-dependence in a key demographic trait, the time that spring reproduction commences after the winter, much work remains to be done in identifying the mechanism(s) responsible for this. We stress the potential for synergistic effects between plant responses to grazing and the prevalence and impact of infection by a diverse pathogen community.

Acknowledgements - This study was funded by NERC grants to XL, a Welcome Trust grant to MB and XL and the Norwegian Research Council (to TE). We are grateful to the Forestry Commission for providing accommodation and permission to work on their land. We acknowledge the contributions of Sarah Burthe, James L MacKinnon, Isla M. Graham and David Tidhar to vole trapping, and we thank Ivan Markovsky for advising us on the use of the EW-TLS procedure.

\section{References}

Aars, J. and Ims, R. A. 2002. Intrinsic and climatic determinants of population demography: the winter dynamics of tundra voles. - Ecology 83: 3449-3456.

Benton, T. G. et al. 2006. Complex population dynamics and complex causation: devils, details and demography. - Proc. R. Soc. B 273: 1173-1181.

Berger, P. et al. 1981. Chemical triggering of reproduction in Microtus montanus. - Science 214: 69-70.

Berryman, A. (ed.) 2002a. Population cycles: the case for trophic interactions. - Oxford Univ. Press.

Berryman, A. 2002b. Population cycles; causes and analysis. - In: Berryman, A. (ed.), Population cycles: the cause of trophic interactions. - Oxford Univ. Press, pp. 3-28.

Bierman, S. M. et al. 2006. Changes over time in the spatiotemporal dynamics of cyclic populations of field voles (Microtus agrestis L.). - Am. Nat. 167: 583-590.

Boutin, S. 1990. Food supplementation experiments with terrestrial vertebrates: patterns, problems and the future. - Can. J. Zool. 68: 203-220.

Bronson, F. H. and Heideman, P. D. 1994. Seasonal regulation of reproduction in mammals. - In: Knobil, E. and Neill, J. D. 
(eds), The physiology of reproduction. Raven Press, NY, pp. 541-583.

Burthe, S. et al. 2008. Cowpox virus infection in natural field vole Microtus agrestis populations: significant negative impacts on survival. - J. Anim. Ecol. 77: 110-119.

Chao, A. et al. 1992. Estimating population size for capturerecapture data when capture probabilities vary by time and individual animal. - Biometrics 48: 201-216.

Chitty, D. 1967 . The natural selection of self-regulatory behaviour in animal populations. - Proc. Ecol. Soc. Australia 2: 51-78.

Clutton-Brock, T. H. and Coulson, T. 2002. Comparative ungulate dynamics: the devil is in the detail. - Phil. Trans. R. Soc. B 357: 1285-1298.

Dobson, F. S. and Oli, M. K. 2001. The demogaphic basis of population regulation in Columbian ground squirrels. - Am. Nat. 158: 236-247.

Ergon, T. 2007. Optimal onset of seasonal reproduction in stochastic environments: when should overwintering small rodents start breeding? - Ecoscience 14: 330-346.

Ergon, T. et al. 2001a. Life-history traits of voles in a fluctuating population respond to the immediate environment. - Nature 411: 1043-1045.

Ergon, T. et al. 2001b. Mechanisms for delayed density-dependent reproductive traits in field voles, Microtus agrestis: the importance of inherited environmental effects. - Oikos 95: 185-197.

Ergon, T. et al. 2004. Optimal body size and energy expenditure during winter: why are voles smaller in declining populations? - Am. Nat. 163: 442-457.

Ergon, T. et al. 2009. Estimating latent time of maturation and survival costs of reproduction in continuous time from capture-recapture data. - In: Thompson, D. et al. (eds), Modeling demographic processes in marked populations. Springer, pp: $173-197$

Graham, I. M. and Lambin, X. 2002. The impact of weasel predation on cyclic field-vole survival: the specialist predator hypothesis contradicted. - J. Anim. Ecol. 71: 946-956.

Hansson, L. 1990. Ultimate factors in the winter weight depression of small mammals. - Mammalia 54: 397-404.

Hansson, L. 1992. Fitness and life history correlates of weight variations in small mammals. - Oikos 64: 479-484.

Innes, D. G. L. and Millar, J. S. 1995. Correlates of lifehistory variation in Clethrionomys and Microtus (Microtinae). - Ecoscience 2: 329-334.

Karban, R. and Baldwin, I. T. 1997. Induced responses to herbivory. - Univ. of Chicago Press.

Korn, H. and Taitt, M. J. 1987. Initiation of early breeding in a population of Microtus townsendii (Rodentia) with the secondary plan compound 6-MBOA. - Oecologia 71: 593-596.

Krebs, C. J. and Myers, J. H. 1974. Population cycles in small mammals. - Adv. Ecol. Res. 8: 267-399.

Lambin, X. et al. 2000. Cyclic dynamics in field vole populations and generalist predation. - J. Anim. Ecol. 69: 106-118.

Lambin, X. et al. 2002. Population cycles: inferences from experimental, modeling and time series approaches. - In: Berryman, A. A. (ed.), Population cycles: the case for trophic interactions. Oxford Univ. Press, pp. 155-176.

Supplementary material (Appendix O18983 at < www.oikos. ekol.lu.se/appendix $>$ ). Appendix 1. MATLAB code used to estimate density dependence in the paper.
Lima, S. L. 1998. Nonlethal effects in the ecology of predator-prey interactions. - Bioscience 48: 25-34.

Markovsky, I. et al. 2006. The element-wise weighted total leastsquares problem. - Comput. Stat. Data Anal. 50: 181-209.

Massey, F. P. et al. 2008. Are silica defences in grasses driving vole population cycles? - Biol. Lett. 4: 419-422.

McCauley, E. and Murdoch, W. W. 1987. Cyclic and stablepopulations - plankton as paradigm. - Am. Nat. 129: 97-121.

Murdoch, W. 1994. Population regulation in theory and practice. - Ecology 75: 271-287.

Norrdahl, K. and Korpimäki, E. 2002. Changes in population structure and reproduction during a 3-year population cycle of voles. - Oikos 96: 331-345.

Oli, M. K. and Dobson, F. S. 2001. Population cycles in small mammals: the alpha-hypothesis. - J. Mammal. 82: 573-581.

Rexstad, E. and Burnham, K. P. 1991. Users guide for interactive program CAPTURE. - Colorado Cooperative Fish and Wildlife Res. Unit, Colorado State Univ., Fort Collins, CO.

Royama, T. 1992. Analytical population dynamics. - Chapman and Hall.

Saitoh, T. et al. 2006. Effects of regime shifts on the population dynamics of the grey-sided vole in Hokkaido, Japan. - Climate Res. 32: 109-118.

Sanders, E. et al. 1981. 6-Methoxybenzoxazolinone: a plant derivative that stimulates reproduction in Microtus montanus. - Science 214: 67-69.

Singleton, G. et al. 2001. Reproductive changes in fluctuating house mouse populations in southeastern Australia. - Proc. R. Soc. B 268: 1741-1748.

Smith, M. J. et al. 2006. Delayed density-dependent season length alone can lead to rodent population cycles. - Am. Nat. 167: 695-704.

Stenseth, N. C. 1999. Population cycles in voles and lemmings: density dependence and phase dependence in a stochastic world. - Oikos 87: 427-461.

Stenseth, N. C. et al. 2003. Seasonality, density-dependence and population cycles in Hokkaido voles. - Proc. Natl Acad. Sci. USA 100: 11478-11483.

Telfer, S. et al. 2005. Infection with cowpox virus decreases female maturation rates in wild populations of woodland rodents. - Oikos 109: 317-322.

Telfer, S. et al. 2007. Contrasting dynamics of Bartonella spp. in cyclic field vole populations: the impact of vector and host dynamics. - Parasitology 134: 413-425.

Turchin, P. 1995. Population regulation: old arguments and a new synthesis. - In: Cappuccino, N. and Price, P. W. (eds), Population dynamics; new approaches and synthesis. Academic Press, pp. 19-40.

Turchin, P. 2003. Complex population dynamics; a theoretical/ empirical synthesis. - Princeton Univ. Press.

Van Huffel, S. et al. 2007. Total least squares and errors-in-variables modeling. - Comput. Stat. Data Anal. 52: 1076-1079.

White, G. C. and Burnham, K. P. 1999. Program MARK: survival estimation from populations of marked animals. - Bird Study 46: $120-139$.

Ylönen, H. 1994. Vole cycles and antipredatory behaviour. - Trends Ecol. Evol. 9: 426-430. 